\title{
LAS CREENCIAS RELIGIOSAS QUE, EN INTERACCIÓN CON LOS IMAGINARIOS CULTURALES, INCIDEN EN LOS PROCESOS CREATIVOS EN LA EDUCACIÓN ARTÍSTICA, EN LOS JÓVENES DE LA INSTITUCIÓN EDUCATIVA MUNICIPAL DE EL TAMBO (N.)
}

\author{
CARLOS ARTURO JIMÉNEZ ORDÓÑEZ \\ Licenciado en Artes Visuales - Universidad de Nariño. \\ Estudiante IV semestre en Maestría en Educación - Universidad de Nariño.
}

\begin{abstract}
RESUMEN
El objeto de estudio de esta investigación son las creencias religiosas y los imaginarios culturales, presentes en los jóvenes y cómo inciden directamente en los procesos creativos en la Educación Artística. Analizaremos los credos en los jóvenes y que tanto tiene de relevancia en los procesos de creación, el cual se tomará el paradigma cualitativo, porque permite una compresión de los imaginarios simbólicos, presentes en estudiantes de grado décimo y once, de la Institución Educativa Municipal Sagrado Corazón de Jesús de EI Tambo, Nariño. Sabemos que hoy en día la secularización (desaparición- trasformación de lo religioso) y la modernidad centrada en el individualismo, hace que haya un vaciamiento de la presencia religiosa, dando fuerza a el nihilismo, el cientificismo y a un desencantamiento del mundo, proceso que ha venido cambiando y en el caso de Latinoamérica de una manera postergada. Por tal razón se investigará desde el enfoque histórico-hermenéutico, donde tenemos cuatro aspectos a analizar hermenéuticamente: Creencias religiosas, Creencias culturales en los adolescentes, rol de las instituciones y las creaciones artísticas, para así discernir e interpretar mejor el mundo cambiante y dinámico.
\end{abstract}

Palabras clave: creencias religiosas, cultura, creatividad, educación artística.

\section{ABSTRACT}

The object of this study of this research is religious and cultural beliefs, present in young people and how they directly affect the creative processes in Art Education. We will analyze the creeds in young people and how important it is in the processes of creation, which will take the qualitative paradigm, because it allows an understanding of the symbolic imaginaries, present in then and eleventh grade students, de la Institución Educativa Municipal Sagrado Corazón de Jesús de El Tambo, Nariño. We know that today secularization (disappearance - transformation of the religious) and modernity centered on individualism, there is an emptying of the religious presence, 
giving strength to nihilism, scientism and a disenchantment of the world, Process that has been changing and in the case of Latin America in a postponed manner. For this reason, it will be investigated from the historical-hermeneutic approach, where we have four aspects hermeneutically analyze: Religious beliefs, cultural beliefs in adolescents, role of institutions and artistic creations, in order to better discern and interpret the changing and dynamic world.

Key words: religious beliefs, culture, creativity, artistic education.

\section{INTRODUCCIÓN}

\subsection{DIÁLOGO ENTRE LAS CREENCIAS, RELIGIÓN Y CULTURA}

\subsubsection{Concepto básico de creencia}

Para entender un poco el concepto básico de creencia tomaremos tres autores que han investigado este tema, como iniciativa, tomaremos las investigaciones del filósofo e investigador mexicano Luis Villoro, también Frank Pajares, docente e investigador de la Universidad de Emoly Atlanta, y por último José Ortega y Gasset filósofo y ensayista español.

Para Villoro1, una creencia es "un estado de disposición adquirido, que causa un conjunto coherente de respuestas y que está determinado por un objeto y situación objetiva aprehendidos" (1982, p. 71). Esa disposición a actuar pone al sujeto en situación de creer, y es mediante la experiencia con el mundo que lo rodea como este logra materializar su creencia. El mismo autor distingue dos tipos de creencias: las primeras las determina como las "creencias básicas", las cuales conforman el trasfondo y el supuesto de nuestro entendimiento del

1. Villoro, L. (1982). Creer, saber, conocer. México: Siglo XXI. mundo; son aquellas heredadas de la sociedad en la que se vive y, por ende, son compartidas por el colectivo. Y las segundas son las creencias de las que, aunque no se expliciten sus razones, al ponerse en situación de duda podrían justificarse.

Es cierto que, quien cree, justificadamente o no, defiende su convicción, pues cree que es real y verdadera. Las creencias pueden ser individuales, o compartidas por un grupo de pertenencia. En general son culturalmente construidas, y se transmiten de generación en generación. Los padres hablan con sus hijos ejerciendo influencia sobre ellos sobre sus creencias valorativas, religiosas, políticas o sociales. Además de esto, explicar una creencia por los motivos es dar cuenta de aquellas motivaciones que llevaron al sujeto a aceptarla como verdadera. Se responde explicando la función que tiene la aceptación de esa creencia en la realización de los deseos, intenciones y necesidades del sujeto.

Ahora bien, Frank Pajares ${ }^{2}$, consideró que las creencias están conformadas de tres componentes: el cognitivo (conocimiento), el afectivo (emoción) y el

2. Pajares, Frank, investigador Universidad de Emoly, Atlanta. 
conductual (acción). Además, señaló que las creencias son un tipo de conocimiento basado en evaluaciones y juicios ligados a la componente afectiva, mientras que el conocimiento se basa en hechos objetivos. Asimismo, este autor considera que la forma de inferir las creencias es a través de la palabra de las personas sobre lo que dicen que pretenden y hacen.

Por otro lado, para Ortega y Gasset (1989), las creencias y las ideas son vivencias que pertenece al mismo género. Pertenecen a la esfera cognoscitiva de nuestro yo, son pensamientos. Que un pensamiento o una idea depende del papel que tenga en la vida del sujeto; por lo tanto, la diferencia entre uno y otro tipo de pensamiento es relativa, relativa a su significación en la vida de cada persona, al arraigo que dicho pensamiento tiene en su mente. No hay que limitar las creencias, como sin embargo se suele hacer, a la esfera de la religión: hay creencias religiosas, pero también científicas, filosóficas y relativas a la esfera de la vida cotidiana.

Cuando intentamos determinar cuáles son las ideas de un hombre o de una época, solemos confundir dos cosas radicalmente distintas: sus creencias y sus ideas. También es bueno aclarar entre "creencias" y las "ideas", donde las creencias constituyen la base de nuestra vida, el terreno sobre que acontece, en cambio, las ideas no poseen en nuestra vida valor de realidad. Actúan en ella precisamente como pensamientos nuestros y sólo como tales.

$\mathrm{Al}$ estar ligadas las creencias con una disposición a actuar, se convierten en carta de navegación que orienta y guía nuestras actuaciones en cada experiencia vivida. Por ello, Ortega y Gasset considera que las "creencias constituyen la base de nuestra vida [] toda nuestra conducta, incluso la intelectual, depende de cuál sea el sistema de nuestras creencias auténticas" (1979, p. 24).

\subsubsection{La religión como una dimensión de la cultura}

Desde otra perspectiva la religión no se puede entender sola, para comprenderla debe estudiarse al lado de otras ciencias como la antropología, la sociología, la psicología, la biología entre otras. Por eso nos acercaremos a la concepción o experiencias de algunos autores de estas disciplinas en torno a su espiritualidad. La religión es un componente de la antropología filosófica entendida como la filosofía del ser humano. Todos estos aspectos serán claves para describir las creencias de los jóvenes, desde aproximaciones teóricas y filosóficas que nos ayuden aclarar la investigación y los diferentes interrogantes. Las creencias religiosas han sido investigadas por diferentes autores modernos y contemporáneos, para acercarnos a aproximaciones cercanas ahondaremos autores que han abarcado y han relacionado las creencias con las prácticas culturales, que será de fundamento para desarrollar este marco teórico.

No hay que olvidar que, la cultura construye identidad y la religión direcciona de una u otra forma la vida de los pueblos o sociedades, por eso existe una fuerte relación entre estas dos dimensiones. La cultura es una marca, es un sello que diferencia las 
comunidades y fortalece el espíritu del hombre religioso y cultural, entre estas dos hay una relación que no es recíproca sino dialéctica, las cuales no pueden separarse, sino que se unen. La cultura se construye desde diferentes campos y prácticas, en donde la creencia religiosa se convierte en el direccionamiento de esta misma, ha esto también se adhiere lo sagrado como acontecimiento verdadero de una cultura, uno de los grandes investigadores como lo es Mircea Elíade nos propone de acuerdo a esta relación lo siguiente:

"En historia de las religiones, toda manifestación de lo sagrado es importante. Todo rito, todo mito, toda creencia o figura divina refleja la experiencia de lo sagrado, y por ello mismo implica las nociones de ser, de significación y de verdad. Como ya dije en otra ocasión, «resulta difícil imaginar cómo podría funcionar el espíritu humano sin la convicción de que existe algo irreductiblemente real en el mundo, y es imposible imaginar cómo podría haberse manifestado la conciencia sin conferir una significación a los impulsos y a las experiencias del hombre ${ }^{3}$ ", (Eliade, 1997: 18).

Podemos decir que, cada sociedad construye su propia cultura y cada hombre la vuelve inmortal. Todas las teorías, creencias y manifestaciones espirituales han permitido que la dimensión religiosa del hombre sea uno de los pilares de la vida del ser humano y símbolo ante un grupo o una sociedad. La cultura revela las relaciones del

3. Elíade. Historia de las creencias y las ideas religiosas. Ediciones Paidós Ibérica S.A. 1987. hombre entre sí y con la naturaleza, es ante todo transformación de lo exterior y de sí mismo, pero también conservación de lo anterior que se hereda, pues la cultura es acumulativa también, trasciende su época y su espacio inmediato original. Es por eso que la religión y la cultura se ligan totalmente y crean un mundo imaginario que se representa en los quehaceres diarios, dándole una interpretación completamente armónica con la naturaleza y la cosmogonía de los seres humanos.

Bueno, también será exequible precisar el concepto de "religión" analizando a diferentes investigadores, esto significaría que la concepción del término religión tendría la simple función de delimitar vagamente un espacio, en cuyo interior sería posible plantearse algunos interrogantes importantes para la existencia humana. No obstante, los intentos en definir las concepciones en torno a la religión y al hecho religioso han sido numerosos y variados. El antropólogo rumano Mircea Elíade se refería a este fenómeno desde la observación de los pueblos antiguos y venía a afirmar que el ser humano es ante todo un ser mítico; por eso señala este autor que: "la mayoría de los hombres sin religión comparten, a pesar de todo, pseudoreligiones y mitologías degradadas que no son sino supersticiones y sustitutivos de las religiones" (Eliade,1997: 27).

En cambio, para Emile Durkheim, el hecho religioso es producto del pensamiento colectivo: "la religión 
es una cosa eminentemente social" 4 (Durkheim, 1982: 15). Siguiendo este hilo argumental podríamos afirmar que la religión de un grupo concreto pertenece a los individuos de un lugar determinado, porque todos estos individuos responden a un mismo fenómeno social, diferentes al de otra comunidad.

El pensamiento religioso posee una característica muy peculiar, que permite distinguirlo de otras formas de pensamiento, ya que implica dividir el mundo en dos esferas distintas, una que abarca todo lo que es sagrado y otras que contiene todo lo que es profano. También despiertan interés las similitudes del hecho religioso entre las diferentes comunidades humanas. El propio Durkheim se refiere a estos aspectos de la siguiente manera: "Ya que todas las religiones son comparables, ya que son todas especies de un mismo género, hay necesariamente elementos esenciales que les son comunes" (Durckeim, 1982: 7).

Durkheim destaca una serie de semejanzas en las actitudes rituales que a pesar de la diversidad de las formas que pueden adoptar en diferentes grupos humanos poseen las mismas funciones sociales, culturales y religiosas debido a un determinado modelo de desarrollo común. La antítesis entre lo sagrado y lo profano es el elemento que permite delimitar el ámbito específico de lo religioso. En la interpretación de Durkheim la oposición entre sagrado y

4. Tomado de Emile Durkheim, Las formas elementales de la vida religiosa. Madrid: Akal, (1982).

5. Ibíd., 7 . profano es total, concibiéndose como un hecho universal. Por otra parte, está el antropólogo estadounidense Clifford Geertz, el cual define la religión de la siguiente manera: "un sistema de símbolos que sirven para establecer vigorosos, penetrantes y duraderos estados anímicos y motivaciones en los hombres, formulando concepciones de un orden general de existencia y revistiendo estas concepciones con una aureola de efectividad tal, que los estados anímicos y motivaciones parezcan de un realismo único"6 (Geertz, 1987: 87).

En este sentido, podemos incluir la religión dentro de la esfera de lo cultural, y ver que emplea símbolos sagrados con el objeto de sintetizar comportamientos y costumbres de una comunidad, repercutiendo en su carácter y en su calidad de vida, en su moral y en su visión del mundo. Geertz afirma que los estados de ánimo ocasionados por la actividad religiosa se traducen en experiencias cotidianas. De modo que la religión tendría la función de ayudar a soportar el sufrimiento de la vida, utilizando en su aplicación argumentos trascendentes. Es decir, para Geertz el hecho de que los individuos tengan que soportar adversidades sería la razón de la existencia del hecho religioso, para encontrar una justificación al sufrimiento de la vida, esta sería la causa principal por la que los seres humanos llegan a creer.

Es pues, a partir de esta premisa que explicamos la religión como un

6. Geertz, C. (1987). La religión como sistema cultural en La interpretación de las culturas. Barcelona: Gedisa. 
sistema de creencias, instituciones y prácticas rituales basadas en la convicción colectiva que se tiene de un mundo sobrenatural. Este sistema, a través de códigos morales y éticos, conforma comunidades de individuos que deciden adherirse a él por diversas motivaciones: herencia familiar, tradición cultural, búsqueda personal o por experiencias espontáneas relacionadas con encuentros espirituales.

\section{LA CREATIVIDAD, EL PODER DEL SER HUMANO}

Entender los mecanismos de la creatividad en el arte es algo importante para todos los seres humanos, ya que de ella depende en gran parte nuestra supervivencia como individuos y como especie. Los animales y los seres humanos comunes y corrientes resolvemos problemas todos los días. Es fama que Wolfgang Koehler, psicólogo de la Gestalt ${ }^{7}$, quien estudiaba monos en Tenerife, descubrió que un chimpancé podía alcanzar unos plátanos que estaban fuera de su alcance. Puso en la jaula del mono unos palos que podían

7. La escuela de la Gestalt nació en Alemania, a principios del siglo XX, con la contribución de los investigadores Max Wertheimer, Wolfgang Köhler y Kurt Koffka, quienes postulaban la percepción como el proceso básico de la actividad mental del ser humano, de modo que el resto de las operaciones de naturaleza psíquica, como el pensamiento, el aprendizaje o la memoria, estarían subordinadas al correcto funcionamiento de los procesos de organización perceptual. Para la Gestalt, el ser humano organiza sus percepciones como totalidades, como forma o configuración, y no como simple suma de sus partes. De allí que lo percibido pase de ser un conjunto de manchas a convertirse en personas, objetos o escenas. ser encajados uno dentro del otro. El mono, al principio, usó un solo palo para alcanzar los plátanos. Como esta maniobra probó ser ineficaz, después de estar quieto un tiempo, encajó los dos palos y pudo así tener un palo más largo con el cual pudo alcanzar los plátanos. Esta anécdota de los monos de Koehler puede servir como metáfora de un mecanismo creativo, quizás muy importante: la capacidad de unir dos o más cosas (ideas, objetos, hechos, imágenes, datos, signos matemáticos, palabras, signos musicales, colores, etcétera) para lograr una tercera, nueva. Esta capacidad la hemos llamado imaginación, pero tal vez en el fondo nos estemos refiriendo simplemente a una forma de asociación o relación mental entre las cosas. Éstas no necesariamente tienen que ser conscientes. Lo que en términos psicoanalíticos se ha llamado condensación tiene mucho que ver con esta idea. Sin embargo, es importante aclarar que la condensación es un mecanismo inconsciente y que forma parte del trabajo del sueño.

Ciertamente, en el siglo XX, la expresión "creativo" empezó a aplicarse a lo largo de toda la cultura occidental; se comenzó a hablar de la creatividad en las ciencias, en política, educación, en tecnología, etc. Surgió y se institucionalizó la creencia de que no sólo los artistas pueden ser creativos, sino también las personas activas de otros campos de la cultura. La creatividad es posible en todos los campos de la producción humana. La ampliación del alcance del concepto alteró en realidad su contenido. 
De hecho, el interés por la creatividad y todo lo que lo rodea ha ido creciendo con el tiempo. Varias han sido las disciplinas que se preocupan por su estudio desde planteamientos tan diversos como la filosofía (Tatarkieewicz), la historia (Gombrich), la ciencia (Hadamard, Poincaré, Bohm), siendo cada vez más frecuentes los estudios interdisciplinares. De estas disciplinas han ido surgiendo diferentes enfoques hacia el tema en función de las distintas corrientes y teorías, lo que ha ido multiplicando los aspectos y factores de posibles análisis. Recientemente, otras disciplinas, más jóvenes están empezando también a aportar estudios sobre creatividad desde visiones híbridas entre la teoría y la práctica, como son la ciencia de la comunicación, el diseño, la publicidad o las artes visuales.

Casi todo, lo que nos rodea es producto del ser humano, producto de la imaginación, donde la base principal es la creatividad. Cada invento, cada teoría científica, cada canción, cada programa de computadora, cada obra de arte son producto de una inminente habilidad que toma una pequeña idea y la convierte en un testimonio de la evolución del hombre. La creatividad está presente en todos lados; cuando una persona tiene un problema busca la manera de resolverlo, su cerebro comienza a discernir y a buscar no solo solución a éste, si no causas y consecuencias, busca alternativas apropiadas para eliminar el conflicto y en caso de encontrar solución, trata de diseñar una.

La creatividad no puede actuar o desarrollarse por sí misma, hay que es- timularla, hay que ponerla en práctica para sacar todo el potencial que tiene una persona. Hoy en día, las escuelas tienen como propósito desarrollar ésta habilidad en sus alumnos, y más en los de temprana edad, ya que imponerlos desde pequeños a ser creativos es la clave para que desaten su imaginación.

Una de las características más significativas de la creatividad es la originalidad, ya que distingue a las ideas de las demás y les permite ser únicas. La creatividad puede surgir en algunas personas de manera espontánea, sin reflexionar o analizar alguna situación o suceso. Puede surgir al escuchar una palabra, al mirar algo familiar o al sentir algo. En otras personas surge al llevar a cabo un análisis, una reflexión o al persistir en encontrar o crear alguna idea original.

\subsection{La creatividad como capacidad humana}

La creatividad se concibe como capacidad humana frente a las antiguas concepciones que la consideraba una cualidad sobrenatural. Es un potencial que caracteriza y distingue a los humanos respecto del resto de los animales y también maquinas, es una actividad consciente. Algunos teóricos como Margaret Boden han estimulado esta relación y diferencias entre creatividad e inteligencia artificial, concluyendo que la creatividad es estrictamente humana.

Es una actividad libre y no predeterminada, se entiende por responder a estímulos y situaciones no previstos, gracias a la capacidad de autovaloración. La creatividad se basa en la 
libertad de elección y permite ir más allá de la lógica establecida.

Es una capacidad universal que cualquier hombre y mujer por el hecho de serlo posee como potencial, aunque en sentido expandido es una cualidad que se puede atribuir también a grupos o colectivos. Además, es una capacidad que puede desarrollarse en cualquier campo y actividad de la vida y en diferentes etapas de la vida.

La creatividad combina aspectos biológicos con aspectos emocionales. En lo referente al factor biológico conlleva la combinación de un sistema complejo de operaciones cognitivas y desarrollo de múltiples habilidades operativas, considerada como capacidad biológica es innata y hereditaria, nacemos con ella y por tanto es una cualidad potencial.

\subsection{La creatividad como proceso}

La creatividad combina capacidades cognitivas y habilidades diversas con una intencionalidad para conseguir un fin determinado. Esa intencionalidad no necesariamente debe ser consciente en todas las fases del proceso. Saturnino de la Torre $(2003: 65)^{8}$ plantea que: "una característica para diferenciar la cualidad creativa de un proceso es su intencionalidad". Los encuentros novedosos puramente azarosos no podrían ser considerados creativos.

Además de intencionalidad el proceso creativo implica direccionalidad,

8. Torre, S. (2003). Dialogando con la creatividad. De la identificación a la creatividad paradójica. Barcelona: Ediciones Octaedro. trazar un rumbo determinado para conseguir un fin. Un proceso conlleva fases sucesivas desde el planteamiento del problema, pasando por su búsqueda, incubación y elecciones, hasta llegar a un resultado, todo ello dirigido a un objetivo.

\subsection{Es una actividad transformadora}

Podríamos definir como creativa a aquel proceso y conjunto de capacidades que permiten hallar relaciones y soluciones novedosas partiendo de informaciones ya conocidas, abarca no solo la posibilidad de solucionar un problema ya conocido, sino también implica la posibilidad de descubrir un problema allí donde el resto de las personas no lo ven. En relación con esto Gardner propone como acciones propias del individuo creativo "que resuelve problemas con regularidad, elabora productos, o define cuestiones nuevas en un campo" (1998:53) ${ }^{9}$. Esta idea puede ligarse a lo que plantea de la Torre, cuando considera que: "todo acto creativo es una "transacción" entre persona y el medio". Que se resuelve con una trasformación personal de la información percibida

La creatividad no es un fin sino un medio que permite mediante un proceso de elaboración encontrar soluciones a partir de lo existente. El proceso creativo traduce las imágenes que percibimos en ideas, mediante la imaginación permite construir soluciones nuevas a los problemas planteados.

9. Gardner, Howard (1998). Mentes creativas. Una anatomía de la creatividad. Barcelona: Paidós. 


\subsection{Es una acción comunicativa}

La creatividad es un proceso que permite canalizar las ideas y convertirlas en productos (palabras, imágenes, sonidos, objetos) para que puedan ser comunicadas y accesibles a otros. La comunicación es una condición necesaria del proceso creativo. Sin comunicación no hay posibilidad de trasmisión y por lo tanto no sería posible valorar las posibles cualidades creativas de los resultados, su capacidad novedosa, de originalidad o valía.

\subsection{La creatividad como producto}

Debe ser original o novedosa y eficaz. Estos atributos puede que sean los que suscitan un mayor consenso. La originalidad fue el primer rasgo evaluado para reconocer personas creativas. Ser capaz de adoptar soluciones novedosas a los problemas se considera un rasgo esencial de la creatividad, diferenciándose de este modo de las soluciones simplemente correctas, pero ya conocidas. Sin embargo, no todo lo novedoso u original es creativo. No se consideran creativas las soluciones poco eficaces o inadecuadas para resolver un problema planteado. Por lo tanto, deben darse ambos aspectos a la vez novedad y eficacia. Aunque estos factores por si solos tampoco son suficientes para reconocer la cualidad creativa de un resultado.

\section{DISEÑO METODOLÓGICO}

\subsection{Paradigma investigativo}

En la presente propuesta de investigación se utilizará el paradigma cualitativo, que tiene como principal características procesos interpretativos de información y relación más directa con los sujetos objetos de investigación. "El proceso de investigación Cualitativa se selecciona cuando se busca comprender la perspectiva de los participantes (individuos o grupos pequeños de personas a los que se investigará) acerca de los fenómenos que los rodea, profundizar sobre sus experiencias, perspectivas, opiniones o significados"10 es decir, la forma en que los participantes perciben subjetivamente la realidad. Este paradigma se enfoca en un trabajo de fenómeno social, ya que busca la comprensión de las creencias religiosas y cómo éstas afectan el trabajo artístico en los jóvenes y su construcción de identidad.

\subsection{Enfoque investigación}

El enfoque de esta investigación es histórico-hermenéutico, el cual busca reconocer la diversidad, comprender la realidad, construir un sentido a partir de la comprensión histórica y social de un grupo determinado, "busca comprender el que hacer, las particularidades, simbologías, imaginarios, significaciones, percepciones cosmovisiones, etc. (Geertz, Clifford 1990). En la investigación busca comprender el que hacer entre el docente y el estudiante, los testimonios directos e indirectos, los procesos de formación en cuanto identidad creatividad y cultura. Ese método permite tener una conexión con el pasado y evaluar de manera crítica,

10. Roberto Hernández Sampieri, Carlos Fernando Collado, Pilar Baptista Lucio. Metodología de la investigación (2010) quinta edición, Mc GrawHill/ Interamericana Editores, S.A. de C.V. 
a fin de crear un nuevo conocimiento a partir de los relatos tanto individuales como colectivos.

\subsection{Método investigativo}

El estudio se presenta como una investigación etnográfica, para comprender un poco esta investigación analizaremos las bases teóricas de la misma a través de autores que han trabajado este tema. Para iniciar esta investigación se tomó el libro del autor Miguel Martínez Miguelez "La investigación cualitativa etnográfica, en educación", donde propone que la investigación etnográfica el ethnos (estudio de personas que se relacionan entre sí) y la elección de la muestra en este caso serían los fenómenos que se dan en la educación artística con relación a las creencias de los jóvenes, el contexto socio-cultural, las relaciones padres-docentes-alumnos, donde son los estudiantes con sus experiencias, visiones de mundo, representaciones, que articulan un tejido social, dinámico, cambiante y complejo, el cual implica un análisis profundo, se posibilita una interpretación y comprensión desde los propios actores. El objetivo inmediato de un estudio etnográfico es crear una imagen realista y fiel del grupo estudiado, pero su intención y mira más lejana es contribuir en la comprensión de sectores o grupos poblacionales más amplios que tienen características similares.

\section{CONCLUSIONES}

En la observación participante se puede deducir que las creencias religiosas con los procesos creativos en la educación artística, son muy esporádicas ya que a los estudiantes no les interesa demasiado sus productos artísticos, ellos adoptan por rechazar y estar con nuevas imágenes y expresiones gráficas y visuales. En cuanto a las creencias religiosas, en su mayoría los estudiantes, son católicos practicantes, pero no se quieren comprometer con los rituales llevados por esta doctrina religiosa. En torno a los imaginarios culturales, está presente el fervor que tuvieron sus antepasados por las imágenes religiosas, es el caso de "el Señor de El Tambo", palpable en el folclore de los habitantes, trasmitido de generación en generación, pero por cuenta de las creencias religiosas emergentes y la pérdida de credibilidad de la iglesia, muchos jóvenes se han apartado de esta forma religiosa. 


\section{BIBLIOGRAFÍA}

Bernard, H. (1994). Research methods in qualitative and quantitative approaches. Londres: SAGE.

Borobio, D. Razones de fe ante la increencia hoy. Artículo. Por Universidad Pontificia de Salamanca - España. Conferencia Cali, Feb. 26 de 2010.

Durkheim, E. (1982). Las formas elementales de la vida religiosa. Madrid: Akal.

Eliade, M. (1970). Historia de las creencias y las ideas religiosas. Tomo I. Barcelona, Buenos Aires, México: Paidós S.A.

Eliade, M. (1981). Lo sagrado y lo profano, cuarta edición. Traducción Luis Gil. Guadarrama, Punto Omega.

España, G. (1999). Mutis y la Expedición Botánica. Bogotá: Panamericana Editorial Ltda.

Firolamo, G., Massenzio, M., Raveri, M., Scarpi, P. (2000). Historia de las religiones. Barcelona: Crítica.

Geertz, C. (1973). La interpretación de las culturas. Barcelona: Gedisa.

Mucchielli, R. (1974). El cuestionario en la encuesta psicosocial. Madrid: Ibérico Europea de Ediciones.

Murillo, F. J. y Martínez-Garrido, C. (2010). Investigación etnográfica. Madrid: UAM.

Ortega y Gasset, J. (1986). Ideas y creencias. Buenos Aires: Revista de Occidente/Alianza.

Pajares, M. F. (1992). Teachers' beliefs and educational research: Cleaning up a messy construct. Review of Educational Research, 62(3), 307-332.

Torre, S. de la (2003). Dialogando con la creatividad. De la identificación a la creatividad paradójica. Barcelona: Ediciones Octaedro.

Turner, V. (1999). La selva de los símbolos. México: Siglo XXI.

Villoro, L. (1982). Creer, saber, conocer. México: Siglo XXI. 